\title{
Erratum to: Preliminary findings of arterial embolization with balloon-occluded and flow-dependent histoacryl glue embolization in a swine model
}

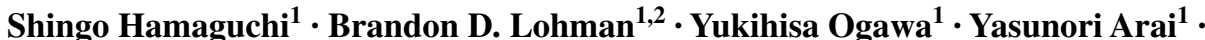 \\ Kazuki Hashimoto $^{1} \cdot$ Junichi Matsumoto $^{2} \cdot$ Yasuo Nakajima $^{1}$
}

Published online: 22 May 2015

(C) Japan Radiological Society 2015

\section{Erratum to: Jpn J Radiol}

DOI 10.1007/s11604-015-0426-1

Unfortunately, an error appeared in the Abstract of the above-mentioned article. In the Results section of the Abstract, a $p$ value of 0.012 was incorrect and should be 0.039 , as shown in the Results section of the main text.

The online version of the original article can be found under doi:10.1007/s11604-015-0426-1.

Shingo Hamaguchi

ha129120@me.com

1 Department of Radiology, St. Marianna University

School of Medicine, Sugao 2-16-1, Miyamae-ku,

Kawasaki 216-8511, Japan

2 Department of Emergency and Critical Care Medicine,

St. Marianna University School of Medicine, Sugao 2-16-1,

Miyamae-ku, Kawasaki 216-8511, Japan 